\title{
Racialized Emotional Labour: The Weight of Blackness in White Spaces
}

Octavia Andrade-Dixon

At the age of 17, from April 2016 to September 2016, I worked part-time at a yacht club on Toronto Island as a maintenance worker. I worked alongside another individual in the maintenance department, and we were both of Afro-Jamaican descent. The club had a predominantly white membership, with few customers who were people of colour. The staff was also mostly white, and there were only five other people of colour who worked there besides us, and none of them were black either. I found that, while interacting with members, I faced racialised remarks and assumptions based on my position as a maintenance worker and as a young black woman. To remain professional and avoid validating any of their racist assumptions, I employed a high level of emotional labour and restraint. In discussions with my Jamaican colleague, I found he faced similar racialised comments; he also felt it necessary to employ emotional control to uphold a palatable image. However, I also found that the non-black employees did not employ the same level of emotional labour. This is not an isolated experience. I have also had to engage in emotional labour in other workplaces. Moreover, it is common to hear about Black employees, especially Black women, performing emotional labour for nonblack customers. Black female employees must employ more emotional labour when working in predominantly white spaces, especially in racialised occupations.

\section{Historicizing Janitorial work}

Janitorial and maintenance work has historically been an occupation that has gendered and racialised biases (Soni-Sinha and Yates 737). Within the American context, Black women were forced to join the labour economy immediately after the abolition of slavery. Black women were often exempt from the notion that women belonged at home because of their racialised identities (Glenn 95). The majority of Black women used the skills they had acquired while enslaved to become domestics in white households, whether they chose to stay in the south or migrate north. However, the labour market for domestic work was not only occupied by black women but by lower-class white women and racialised Irish women as well. With this competition, Black women were thus made to do the most strenuous and dirty work in the household (Taylor Phillips 396). Canada also has histories of Black women engaging in domestic work post abolition of slavery. One example is the Caribbean Domestic migration scheme.

The Caribbean Domestic Scheme only allowed Caribbean women to immigrate to Canada as domestic workers (Calliste 132). While Canada was the requesting nation, it had egregious restrictions on women's entrance to the country, such as barring entry to women who were suspected of having the potential to abuse the system by getting pregnant (Calliste 134). Black Caribbean women faced a multitude of racialised assumptions when entering the domestic work scheme, they and did not have the opportunity to combat those assumptions or to advance socially because of the restrictions of the program and their socio-economic status.

At present, the disenfranchisement of Black women with little education is still prevalent, and they often occupy jobs in janitorial or domestic work. Due to these histories and the stigmas associated with occupations dealing with cleaning, my family was not very receptive to the news of my employment. As someone of Jamaican descent, whose family did not have to come to Canada through domestic schemes, but instead had the means to obtain other employment, my 
mother could not fathom why I would take a position of such low social standing. I, too, was not proud of my first job because of stigma attached to it, and I would say I was waitressing at the yacht club rather than cleaning when asked about it.

Besides the stigma of janitorial work, it is a gendered occupation that recreates gendered divisions of labour through the distribution of tasks. Janitorial work has two classifications: heavy duty and light duty (Soni-Sinha and Yates 740). Heavy-duty work includes "mopping and waxing floors and carrying rubbish to the chute," while light work includes "vacuuming, dusting, and cleaning bathrooms" (Soni-Sinha and Yates 746). Divisions of janitorial work are done based on the general notion that women should not do more physically laborious tasks (SoniSinha and Yates 740). Women are often paid less and shown less respect for their labour because of this. However, employers have tended to disregard these gender roles when it comes to Black women and to blur the distinction between heavy work and light work if it is Black women who have to take it on. Historically, Black women in domestic work have had to carry out all tasks at a toilsome rate (Glenn 96). The division of labour at the club was very apparent, as I typically performed soft tasks such as dusting, vacuuming, and cleaning the washrooms. My male coworker would perform heavy tasks such as mopping and cleaning the yard. While my male coworker did not do all heavy labour when I did engage in it, it was with his assistance. These historically racialised and gendered norms in janitorial remain and add to the additional labour that black women must employ in these positions.

\section{Emotional Labour as a Black woman}

Hochschild describes emotional labour as the controlling and presenting of one's emotions and to create a positive emotional state in another person (552). However, her work does not encompass the differing experiences of women from varying ethnic backgrounds. Her point of view predominantly describes the single-faceted oppression that white women face as women in society. However, Black women do not encounter only one facet of oppression; instead, they must navigate multi-layered oppressive standards that intersect their position as both women and Black people (Glenn 95).

While working at the club, I felt the gravity of how my race and gender intersected when speaking to colleagues and members. Comments made by those I interacted with were harmful to one or more facets of my identity. It was as if they believed the comments would not affect me because of their binary view of me as either a Black person or as a woman (Hill Collins 70). Emotional labour for Black women comes with the responsibility of conforming to the standards upheld by white society (Durr and HarveyWingfield 558).

For example, Black women often engage in code-switching, changing the register they use to speak with co-workers (Durr and Harvey Wingfield 558). Code-switching is a defence mechanism used to make those they are speaking with more comfortable. There is the assumption that Black women talk in a harsh, uneducated manner (Hill Collins 69). Thus, they adopt a sweeter, more formal voice when talking to unfamiliar people. When I spoke to members of the club, I would speak in a higher octave, and adopt different colloquialisms. I did this so I would seem less assuming towards the customer and to avoid triggering negative stereotypes about my identity.

There is often an unspoken sense of responsibility to present the best version of oneself when around non-Black people, because it feels as though our actions are viewed collectively 
rather than individually. Moreover, Black women not only adopt different speaking patterns to make customers comfortable but different mannerisms as well. They will often shrink themselves in situations to appear as the most agreeable employee (Hill Collins 56). They will remain quiet "speak when spoken to" (Durr and Harvey Wingfield 565), and attempt to take up the least amount of space. Because I could listen to music at work, I would often dance while working. If I heard someone coming, I would immediately stop. Further, if a member came into a room I was cleaning, I would quickly try to move what I was doing so I would take up less space and not get in their way.

Another way in which Black women perform emotional labour in predominantly white areas is by stomaching insensitive comments so as not to seem confrontational (Durr and Harvey Wingfield 566). When voicing a concern, people misconstrue Black women's intentions as being unnecessarily argumentative or divisive. To avoid unnecessary conflict and isolation, Black women silence themselves to avoid creating discomfort at their own expense. There were multiple occasions when members or my superiors would make comments that were inappropriate, and I would smile and nod to avoid conforming to the "angry Black girl" trope. In one instance, a member asked me if I was doing my fifth year of school, based solely on his assumption of me as a young Black woman working in maintenance. Instead of allowing myself to react or explaining to him why his comments were harmful, I just told him no, that I was attending UofT in the fall. While leaving his comment unchecked allowed him to perpetuate more anti-Black microaggressions in the future, I had to pick emotional preservation over performing more emotional labour to educate this man. I also had to weight the potential risk to my job if he complained to management. The self-imposed restrictions based on long-standing teachings and the desire to disprove societal anti-Blackness leads Black women to be overly performative when working in non-black spaces. These patterns are prevalent in all workforces, but working in racialised service work exacerbates them, as interactions with customers are the main component of their employment.

\section{Comparative levels of Emotional Labour}

The performance of emotional labour is common to those who work in the service industry. However, the distribution of emotional labour required of employees is unequal. I found while working at the yacht club that my co-workers enacted different levels of emotional labour based on the axes of their identities. Emotional labour theory focuses on the creation of emotions in other (Hochschild 552). Thus, the amount of emotional labour needed is dependant upon the receiver's perception of the performer. As emotional labour is often a racialised action, depending on the demographics of the space, different levels would be necessary for the in-group to feel comfortable. In non-Black spaces, whether they are predominantly white or otherwise, Black women are continually outsiders in their places of employment (Hill Collins 70). Black women then implement more emotional labour to move more comfortably in these spaces (Durr and Wingfield 559). I used different vocal intonations, colloquialisms and changed my mannerisms because I had the subconscious desire to make the predominantly white clientele comfortable.

However, I found that two of my co-workers in the maintenance department did not perform as much emotional labour, or attempt to maintain the same degree of professionalism at work. One of my co-workers was a young white woman who was the same age as me, but her boyfriend was a member of the yacht club. From the beginning of her employment, there was a 
sense of comfort that I did not share. This was because she was already a part of the in-group at the club. While I was a visible minority at the club, she could take off her uniform and blend into the social circles of the club. As a result, she would use her privilege to take liberties on the job, such as sleeping in the TV room and moving through the space as though she were a patron.

My second co-worker was a Latino man who worked at the club for over fifteen years. Unlike my other co-worker, he had a marginalised identity as a Latino man. Consequently, he did not disregard emotional labour as she did. Nor, however, did he employ the same kind of emotional labour as I did: he did not attempt to shrink himself or become more palatable, but would become a performative caricature of himself. Although he did have an eclectic personality, I saw that he frequently presented a sensationalised version of himself to others. For the customers' comfort he allowed himself to be tokenized and placed into a crazy Latino trope (Kanter 211). This performative personality permitted him more liberties in his conduct, since no one expected him to perform at a high level in his work. He would leave the yacht club for hours and drive around the island on a golf cart on garbage runs that could be accomplished in under an hour. The way management and clientele perceived my coworkers enabled their lack of regard for their work to become a long-standing pattern, a luxury I did not feel I could afford.

\section{Conclusion}

Black employees have the added pressure of performing increased amounts of emotional labour while working in racialised service positions such as janitorial work. I felt this pressure while working in maintenance at the yacht when I was just out of high school. Janitorial work as a modern successor of domestic work holds many of the same racialised and gendered roles. Domestic work was a prevalent occupation for Black women in North America, whether they were Black American or Black Caribbeans immigrating to Canada, and these women were subject to substandard work conditions and duties. Currently, Black women still face poor working conditions in janitorial work due to their position in society. Further, in these marginalised positions, interactions with patrons and non-Black co-workers require additional labour beyond the physical demands of the job, often in the form of emotional labour.

Emotional labour manifests more prominently for Black women in non-Black spaces as they use it as a tool for assimilation and self-perseveration. Although emotional labour in service work is not exclusive to Black women, other marginalised groups employ varying degrees because the axes of their identity provide them with less need to perform emotional labour, based upon customers' perceptions. Thus, because of Black women's unique place in society, we are met with the added responsibility of protecting ourselves in unwelcoming spaces. However, to lessen this burden, the public needs to be educated. But whose responsibility is it? In a society that already profits off the continual labour of Black women, we should not be the educators, but the spectators in society's collective unlearning. 


\section{Works Cited}

Calliste, A. (1994). Race, Gender and Canadian Immigration Policy: Blacks from the Caribbean, 1900-1932. Journal of Canadian Studies, 28(4):131-148.

Durr, M. and Harvey Wingfield, A. (2011). Keep Your ' $N$ ' in Check: African American Women and the Interactive Effects of Etiquette and Emotional Labor. Critical Sociology, 37(5): 557-571.

Glenn, E. (1985). Racial Ethnic Women's Labor: The Intersection of Race, Gender and Class Oppression. Review of Radical Political Economics, 17(3): 86-108.

Hill Collins, P. (2000). Black feminist thought. 1st ed. New York: Routledge: 50-80.

Hochschild, A. (1983). Emotional work, feeling rules, and social structure. American Journal of Sociology 85(3): 551-575.

Kanter, R. (2008). Men and Women of the Corporation. New York: Basic Books.

Soni-Sinha, U. and Yates, C. (2013). 'Dirty Work?' Gender, Race and the Union in Industrial Cleaning. Gender, Work \& Organization: 737-751.

Taylor Phillips, D. (2013). Moving with the Women: Tracing Racialization, Migration, and Domestic Workers in the Archive. Signs: Journal of Women in Culture and Society, 38(2): 379404. 